International Journal of Engineering, Science and Technology Vol. 2, No. 11, 2010, pp. 50-59
INTERNATIONAL JOURNAL OF ENGINEERING, SCIENCE AND TECHNOLOGY

www.ijest-ng.com

(C) 2010 MultiCraft Limited. All rights reserved

\title{
Development of light weight ALFA composites
}

\author{
J. Babu Rao*, D. Venkata Rao and N.R.M.R. Bhargava \\ Department of Metallurgical Engineering, Andhra University, Visakhapatnam - 530 003, INDIA \\ ${ }^{*}$ Corresponding Author: e-mail:baburaojinugu@yahoo.com
}

\begin{abstract}
Composites are most promising materials of recent interest. Metal matrix composites (MMCs) possess significantly improved properties compared to unreinforced alloys. There has been an increasing interest in composites containing low density and low cost reinforcements. Among various dispersoids used, fly ash is one of the most inexpensive and low density reinforcement available in large quantities as solid waste by-product. In the present investigation, pure aluminium -5 to $15 \%$ (by weight) fly ash composites were made by stir casting route. Phase identification and structural characterization was carried out on fly ash by X-ray diffraction studies. Scanning electron microscopy and optical microscopy was used for microstructure analysis. There was a uniform distribution of fly ash particles in the matrix phase and also existing a good bonding between matrix and fly ash. The hardness of the composites increased whereas the density of the composites decreased with increasing the amount fly ash than the pure aluminium. Enhanced mechanical properties were observed with increasing amount of fly ash under compression.
\end{abstract}

Keywords: Light metals, Aluminium, MMCs, Fly Ash, Stir casting

\section{Introduction}

In the recent years, usage of ceramic particle - reinforced metal matrix composites (MMCs) is steadily increasing because of their advantages like isotropic properties and the possibility of secondary processing facilitating fabrication of secondary components. Aluminium matrix composites (AMMCs) have gained wide acceptance in the past three decades due to their high specific strength and stiffness and superior wear resistance (Surappa et al., 1981; Vasudevan et al., 1990; Arsenault et al., 1991; Pramila Bai et al., 1992). There has been an increasing interest in composites containing low density and low cost reinforcements (Seah et al., 2003; Siddiquea et al., 2008; Belger et al., 2006; Sulaiman et al., 2008). Rohatgi et al. (2010) showed the increase in density and hardness with increase in amount of silica sand of A206 aluminium alloy containing silica sand particles. Dry sliding wear behaviour of silicon particles reinforced aluminium matrix composites was reported by Zhiqiang et al. (2005); the results showed that silicon particle- reinforced composites exhibited reduced wear loss than the unreinforced alloy specimens. Quartz $\left(\mathrm{SiO}_{2} \mathrm{p}\right)$ reinforced chilled metal matrix composite for automotive applications were developed by Hemanth (2009). In his study concluded that the mechanical properties of the chilled composites were superior to those of the matrix alloy. Strength and hardness increase with increase in dispersoid content and this may be possibly because of the occurrence of a more uniform distribution of $\mathrm{SiO}_{2}$ particles within the matrix.

Among various dispersoids used, fly ash is one of the most inexpensive and low density reinforcement available in large quantities as solid waste by-product during combustion of coal in thermal power plants. Fly ash particles are classified into two types, precipitator and cenosphere. Generally, the solid spherical particles of fly ash are called precipitator fly ash and the hollow particles of fly ash with density less than $1.0 \mathrm{~g} / \mathrm{cm}^{3}$ are called cenosphere fly ash. The precipitator fly ash, which has a density in the range of 2.0-2.5 g/ $\mathrm{cm}^{3}$ can improve various properties of selected matrix materials, including stiffness, strength and wear resistance and reduce the density. Cenosphere fly ash, which consists of hollow fly ash particles, can be used for the synthesis of ultra light composite materials due to its significantly low density, which is in the range of $0.4-0.7 \mathrm{~g} / \mathrm{cm}^{3}$, compared with the densities of metal matrices, which is in the range of $1.6-11.0 \mathrm{~g} / \mathrm{cm}^{3}$. One common type of fly ash is generally composed of the crystalline compounds such as quartz, mullite, hematite, glassy compounds such as silica glass, and other oxides. Hence, composites with fly ash as reinforcement are likely to overcome the cost barrier for wide spread applications in automotive and 
small engine applications. It is therefore expected that the incorporation of fly ash particles in aluminium alloy will promote yet another use of this low-cost waste by-product and, at the same time, has the potential for conserving energy intensive aluminium and thereby, reducing the cost of aluminium products (Rohatgi, 1994; Rajan et al., 2001; Rohatgi et al., 1997).

In view of the above said advantages with fly ash additions as reinforcements in AMMCs, the present investigation makes an attempt to synthesize the pure aluminium- fly ash (ALFA) composites $(5,10$ and $15 \%$ fly ash by weight) with stir casting route and focused to characterize the enhanced mechanical properties in terms of hardness, density and compression strength for these newly developed ALFA composites.

\section{Experimental work}

\subsection{Processing of as received fly ash}

In the present study, aluminium based metal matrix (ALFA) composites containing 5\%, 10\% and 15 wt. \% fly ash particulates were successfully synthesized by stir cast (vortex) method. The matrix materials used in this study was commercial pure aluminium (99.5\%). The reinforcement material was fly ash particulates, which were procured from Thermal power plant of RINL, Visakhapatnam Steel Plant, Visakhapatnam, India. The chemical composition of the as received fly ash sample was given in Table 1. A 500 grams weight of fly ash sample was taken in a graphite crucible and allowed to preheat in the muffle furnace at $800^{\circ} \mathrm{C}$ for 3 hours to find out the loss on ignition and it was found to be $2.4 \%$. Preheated fly ash after cooling to room temperature was washed in distilled water and removed the carbon that creamed up during washing. It was then dried at $110^{\circ} \mathrm{C}$ for 48 hours to get rid of water. Dried fly ash has been sieved for 15 minutes using BSS meshes ranging in size from 100 to 350 by Rotap Sieve shaker. The results show that more than $70 \%$ by weight retained in $-200+350$ mesh with an average particle size of $60 \mu \mathrm{m}$; hence this size was chosen as reinforcement for synthesis of Al- fly ash composites.

The colour of fly ash can be tan to dark grey, depending on its chemical and mineral constituents. Tan and light colours are typically associated with high lime content. A brownish colour is typically associated with the iron content. A dark gray to black colour is typically attributed to elevated unburned carbon content. Fly ash colour is usually very consistent for each power plant and coal source. Figure 1 shows the appearance of fly ash before and after heat treatment; from this figure it is evident that after heat treatment (preheat in the muffle furnace at $800^{\circ} \mathrm{C}$ for 3 hours) colour was changed from dark grey to brownish due to the departure of unburnt carbon content associated in the as received condition. The figure 1(b) fly ash was used for making of ALFA composites.

Table 1: Chemical composition of as received fly ash, wt. \%

\begin{tabular}{ccccccccc}
\hline $\mathrm{SiO}_{2}$ & $\mathrm{Al}_{2} \mathrm{O}_{3}$ & $\mathrm{Fe}_{2} \mathrm{O}_{3}$ & $\mathrm{TiO}_{2}$ & $\mathrm{CaO}$ & $\mathrm{MgO}$ & $\mathrm{Na}_{2} \mathrm{O}$ & $\mathrm{K}_{2} \mathrm{O}$ & $\begin{array}{c}\text { Loss on } \\
\text { Ignition }\end{array}$ \\
\hline 58.41 & 30.40 & 8.44 & 2.75 & 1.3 & 1.53 & 1.0 & 1.98 & 2.4 \\
\hline
\end{tabular}

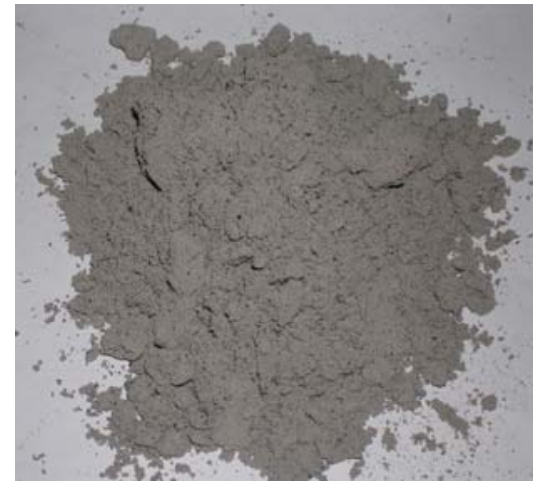

(a)

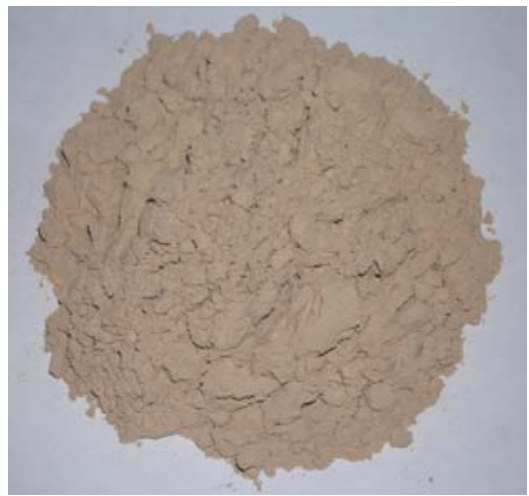

(b)

Figure 1: The fly ash powder used for synthesis of ALFA composites (a) as received condition (b) After heat treatment condition

The chemical constituents of fly ash depend mainly on the chemical composition of the coal. However, fly ashes that are produced from the same source or have very similar chemical composition can have significantly different ash mineralogy's depending on the coal combustion technology that was used. Figure 2 shows the scanning electron micrograph of the fresh fly ash after heat treatment. From this figure it is evident that majority of the fly ash particles are spherical in nature and precipitator type fly ash. The morphology of fly ash particle is controlled by combustion temperature and cooling rate at the thermal power plant. The X-ray diffraction (XRD) pattern of fly ash in as received condition is shown in figure 3, which shows the phases present in the fly ash are largely Silica $\left(\mathrm{SiO}_{2}\right)$, Alumina $\left(\mathrm{Al}_{2} \mathrm{O}_{3}\right)$, Mullite $\left(3 \mathrm{Al}_{2} \mathrm{O}_{3} \cdot 2 \mathrm{SiO}_{2}\right)$ and small quantity of hematite $\left(\mathrm{Fe}_{2} \mathrm{O}_{3}\right)$. 


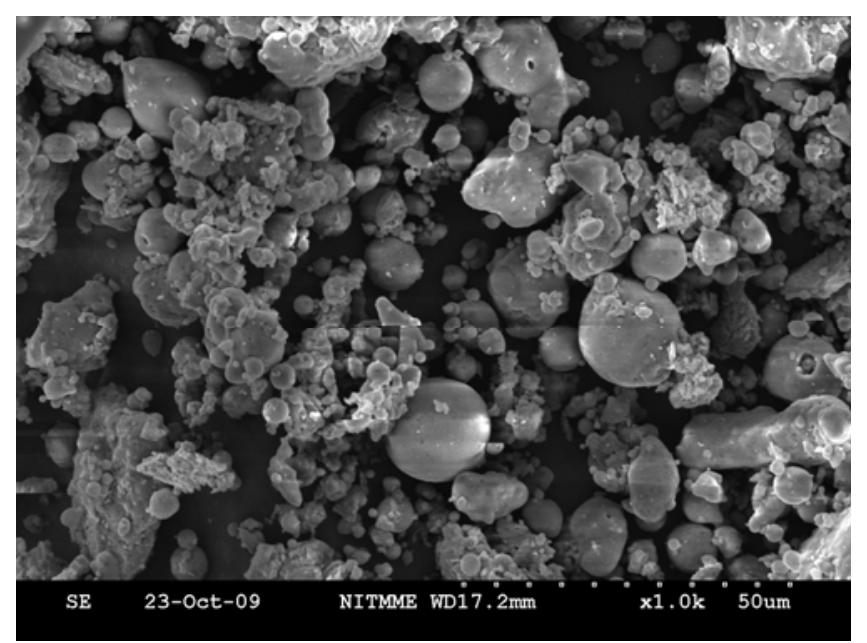

Figure 2: Scanning electron micrograph of fly ash particles used in fabrication of ALFA Composites

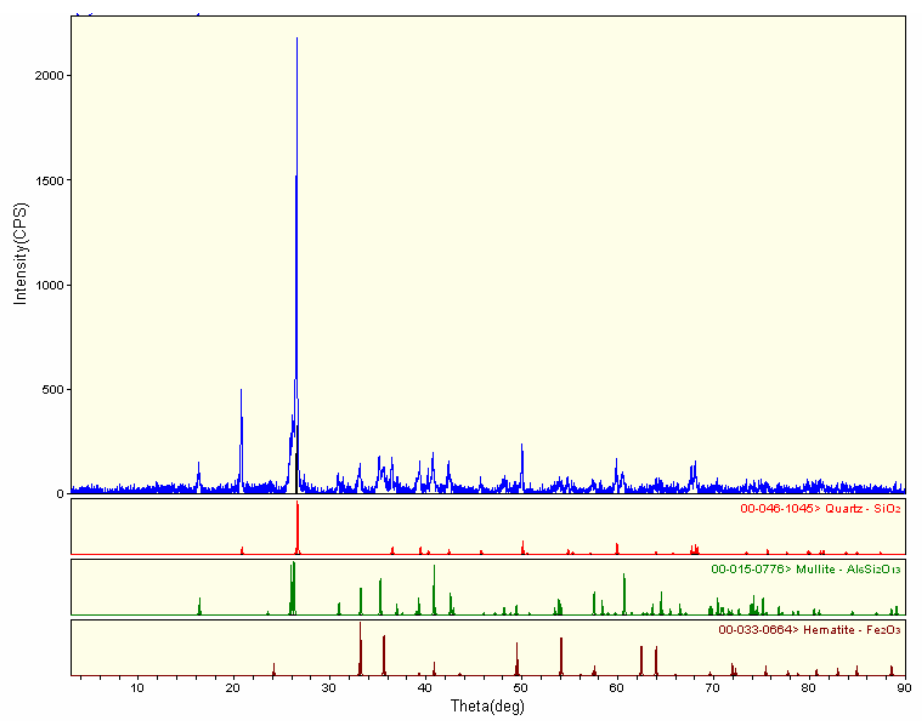

Figure 3: X-ray diffractogram of fly ash particles used in fabrication of ALFA composites

\subsection{Synthesis of Al-Fly Ash composites}

The synthesis of Al-fly ash composites (Al- 5\%, 10\% and 15\% fly ash by wt.) were carried out by stir casting technique. Cylindrical fingers (18 $\mathrm{mm} \Phi$ and $170 \mathrm{~mm}$ length) of pure aluminium were taken into a graphite crucible and melted in an electric furnace. The experimental set up used for making of these ALFA composites was shown in figure 4. After maintaining the temperature at $770{ }^{\circ} \mathrm{C}$, a vortex was created using mechanical stirrer made of graphite. While stirring was in progress, the preheated fly ash particulates at $800^{\circ} \mathrm{C}$ for $2 \mathrm{hrs}$ were introduced, as shown in figure 5(a). Care was taken to ensure continuous and smooth flow of the particles addition in the vortex. The molten metal was stirred at $400 \mathrm{rpm}$ under argon gas cover; stirring was continued for about 5 minutes after addition of fly ash particles to get the uniform distribution in the melt, as shown in figure 5 (b). During stirring small pieces of magnesium $(0.5 \mathrm{wt}$. \%) were added to the molten metal to enhance the wettability of fly ash particles with melt. Still the melt is in stirring condition the melt with the reinforced particulates were bottom poured into preheated $\left(200{ }^{\circ} \mathrm{C}\right)$ S.G. iron mould of $18 \mathrm{~mm}$ diameter and $170 \mathrm{~mm}$ height. Figure $6(\mathrm{a} \mathrm{\&} \mathrm{b})$ shows the photograph of the SG iron metallic die for finger casting and cooled finger castings respectively. Homogenization treatment for these fingers was carried out at $200{ }^{\circ} \mathrm{C}$ for $24 \mathrm{hrs}$. 


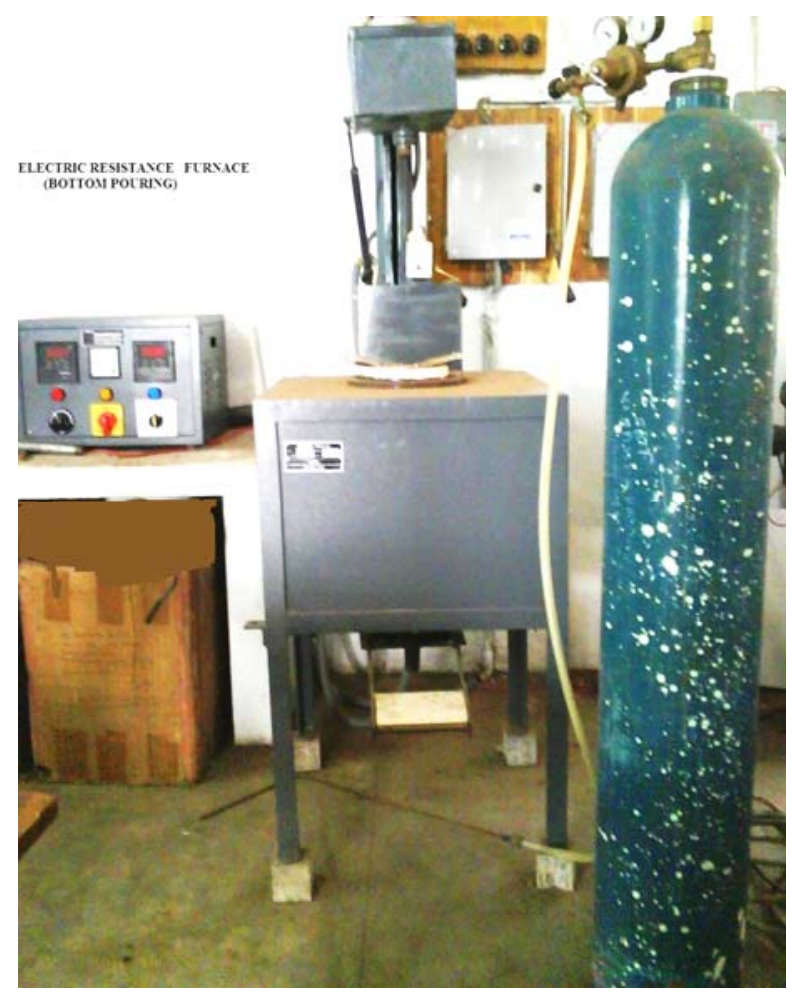

Figure 4: Experimental set up with bottom casting facility for synthesis of ALFA composites

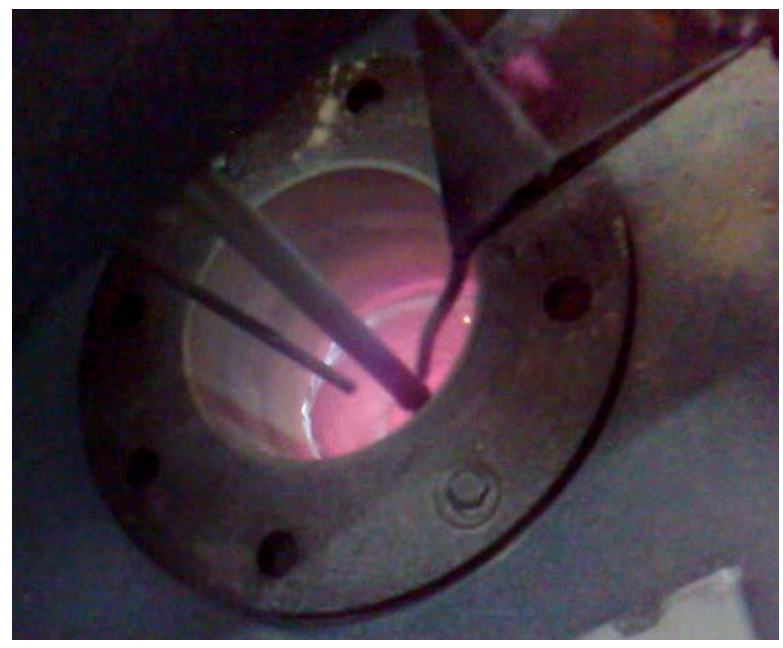

(a)

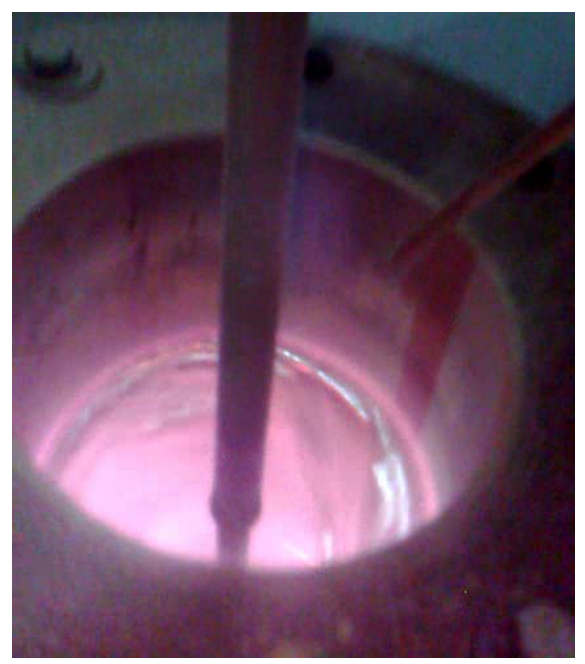

(b)

Figure 5: (a) Experimental view of the fly ash powder addition along with Ar gas shielding after creating a vortex in the aluiminum melt by a mechanical stirrer

(b) Ensuring uniform mixing of fly ash particles in aluminium matrix by uniform stirring along with Ar gas shielding. 


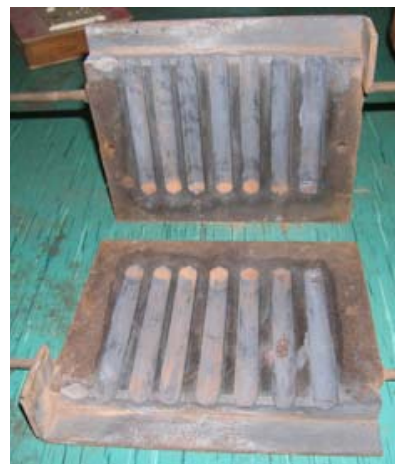

(a)

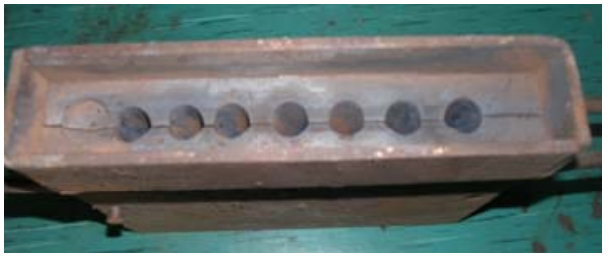

(b)

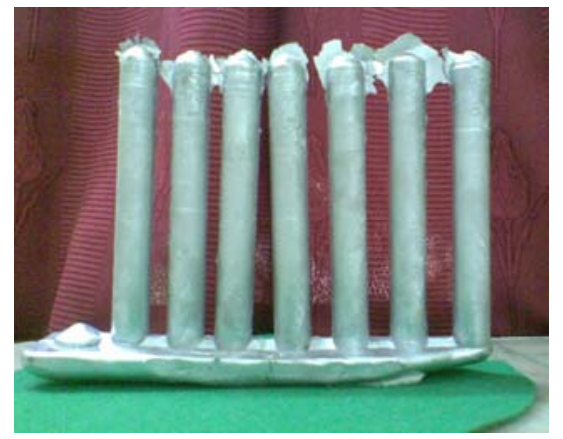

(c)

Figure 6: Photograph of (a) the metallic die for finger casting (b) Finger castings

\subsection{Characterization of Al-Fly Ash composites}

\subsection{1: Metallography studies}

Specimens for metallographic observations were prepared by standard polishing techniques. The microstructures of the specimen were investigated by means of optical microscopy (Model: Olympus, $\mathrm{C}-5060$ - G x 4- Japan). Keller's reagent with composition of $\mathrm{HF}=1.0 \mathrm{cc}, \mathrm{HCL}=1.5 \mathrm{cc}, \mathrm{HNO}_{3}=2.5 \mathrm{cc}$ and $\mathrm{H}_{2} \mathrm{O}=95 \mathrm{cc}$ was used as etching reagent. Scanning electron microscopy (Model: SEM - Quanta 400, FEI -Netherlands) was used in order to evaluate the morphological changes observed in the fly ash powder particles.

\subsubsection{Hardness studies}

The hardness of the pure aluminium and composites was evaluated using Rockwell hardness testing machine with $100 \mathrm{~kg}$ load and $5 \mathrm{~mm}$ diameter steel ball indenter. The detention time for the hardness measurement was 15 seconds. An average of ten readings was taken for each hardness value.

\subsubsection{Density measurements}

The density of the alloy and composites was measured by the Archimedes drainage method by using the following equation (Wu et al., 2006):

$$
\rho_{\mathrm{MMC}}=(\mathrm{m}) /\left(\left(\mathrm{m}-\mathrm{m}_{1}\right) \mathrm{X} \rho_{\mathrm{H} 2 \mathrm{O}}\right)
$$

Where $\rho_{\text {MMC }}$ is the density of the Al-Fly ash composite, ' $\mathrm{m}$ ' is the mass of the composite sample in air, ' $\mathrm{m}_{1}$ ' is the mass of the same composite sample in distilled water and ' $\rho_{\mathrm{H} 2 \mathrm{O}}$ ' is the density of distilled water (at $293 \mathrm{~K}$ ) is $998 \mathrm{~kg} / \mathrm{m}^{3}$.

\subsubsection{Compression Tests}

Compression tests were carried out on cylindrical specimens of pure aluminium and Al-fly ash composites $(5,10$ and $15 \%$ fly ash) of $16 \mathrm{~mm} \varnothing$ with $H_{0} / D_{0}$ ratio of 1.0. These cylindrical specimens of standard dimensions were prepared using conventional machining operations of turning, facing and drilling. Specimen edges were chamfered to minimize folding. Concentric v- grooves of $0.5 \mathrm{~mm}$ deep were made on the flat surfaces to have a low friction between die and work piece during compression. Standard samples were compressed by placing between the flat platens at a constant cross head speed of $0.5 \mathrm{~mm} / \mathrm{min}$ in dry condition, using a computer controlled servo hydraulic 100T universal testing machine (Model: FIE-UTE). Cold work die steel dies (flat flattens) were machined to produce smooth finish to yield low friction. Online plotting of load versus displacement was done continuously through a data acquisition system. 


\section{Results and discussion}

\subsection{Microstructures of ALFA composites}

Figure 7 (a) shows the optical microstructure of commercial pure aluminium. A continuous network in a matrix can be observed from this figure. Commercial pure aluminium is the metal that comes from the reduction of $\mathrm{Al}_{2} \mathrm{O}_{3}$ in the electrolytic cell and it is the bulk of the commercial production. It may contain up to $1 \%$ impurities. These small amounts of impurities form as an almost continuous network in metal of $99 \%$ purity. This network is formed mainly by the iron and silicon constituents; the nature, size and distribution of these constituents is controlled by the Fe/Si ratio and the casting technique. In the aluminium - iron- silicon alloys two ternary compounds are formed, $\mathrm{Fe}_{2} \mathrm{SiAl}_{8}$ and $\mathrm{FeSiAl}_{5}$. In addition $\mathrm{FeAl}_{3}$ and silicon can be present [Mondolfo, 1976]. Figures 7(b-d) shows the optical microstructures of Al -fly ash composites for 5, 10 and $15 \%$ respectively. These revealed that presence of fly ash particles in pure aluminium matrix and further confirm that there was a uniform distribution of fly ash particles in the base matrix; and it clearly shows that there was no voids and discontinuities observed in the composite and also there was a good interfacial bonding between the fly ash particles and matrix materials.

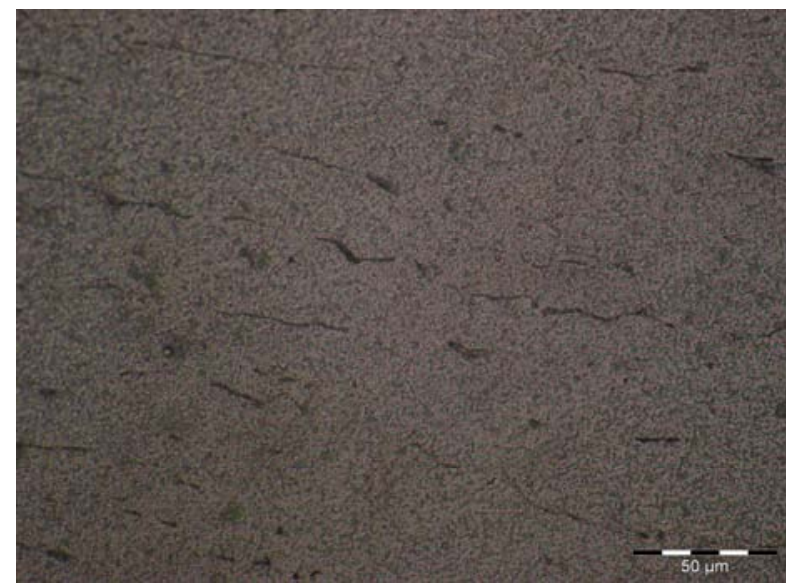

(a) Pure aluminium (500X)

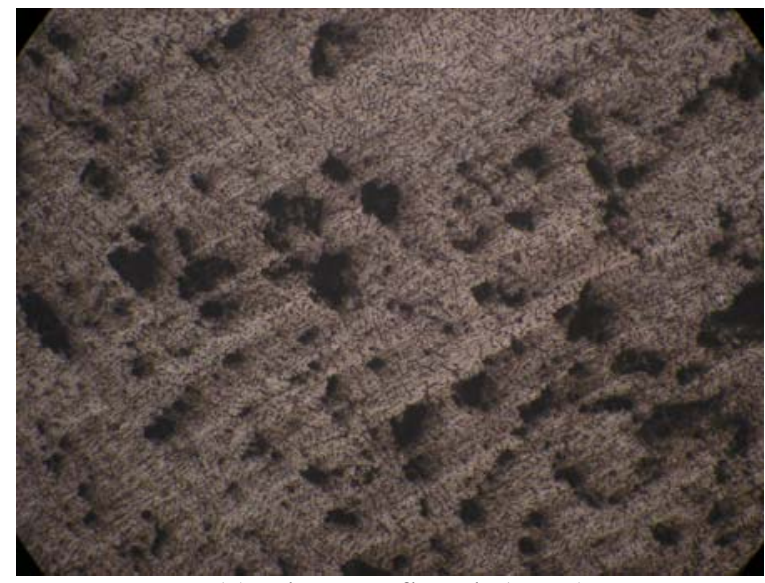

(c) Al - 10\% fly ash $(50 \mathrm{X})$

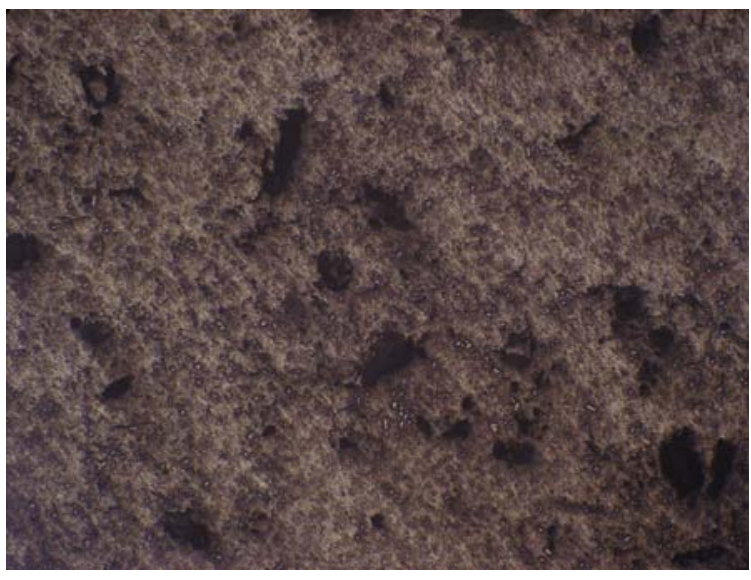

(b) Al - 5\% fly ash (50 X)

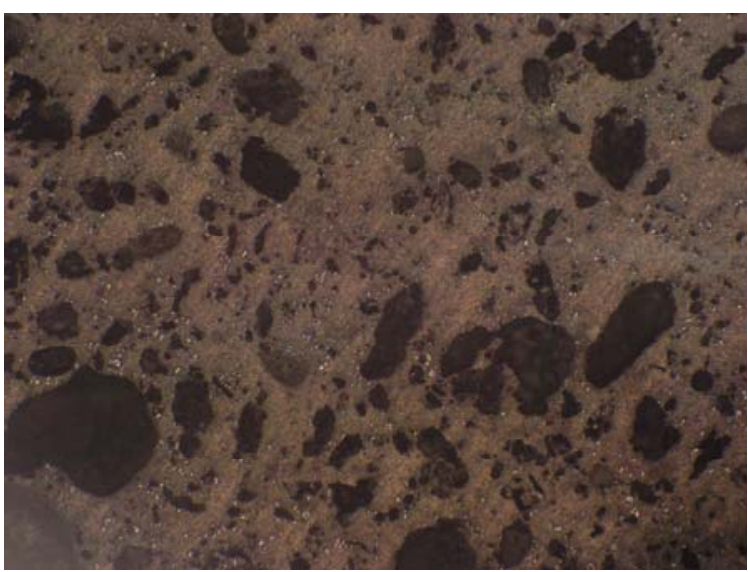

(d) Al - 15\% fly ash (50 X)

Figure 7: (a) Optical micrograph of pure aluminium, at 500 X, Etchant: Keller's reagent.

(b, c \& d) Optical micrographs of as cast Al- fly ash composites, at 50 X, Etchant: Keller's reagent.

\subsection{Mechanical properties of ALFA composites}

Figure 7 shows the hardness of the pure aluminium and Al-fly ash (ALFA) composites in as cast condition. As the amount of fly ash is increasing the hardness of the composite is increasing. This increase was observed from 10 HRB for pure aluminium to 19 , 26 and $45 \mathrm{HRB}$ for 5\%,10\% and 15\% fly ash composites. This could be due to the presence of fly ash particulates which consists of majority of the alumina and silica which are hard in nature. The density of the composites decreases with increasing the percentages of fly ash particulates, as shown in figure 9. The density was come down from 2.72 to $2.454,2.26$ and $1.85 \mathrm{~g} / \mathrm{cc}$ with 0 , 5,10 and 15\% fly ash respectively. Generally the fly ash particles are having low density in nature; the densities of cenosphere and precipitator fly ash were $1.0 \mathrm{~g} / \mathrm{cm}^{3}$ and $2.0-2.5 \mathrm{~g} / \mathrm{cm}^{3}$ respectively; In the present investigation precipitator fly ash was used for synthesis of ALFA composites, since the density of the fly ash is less than $2.09 \mathrm{~g} / \mathrm{cm}^{3}$, hence the overall density of the fly ash composite was got reduced. 


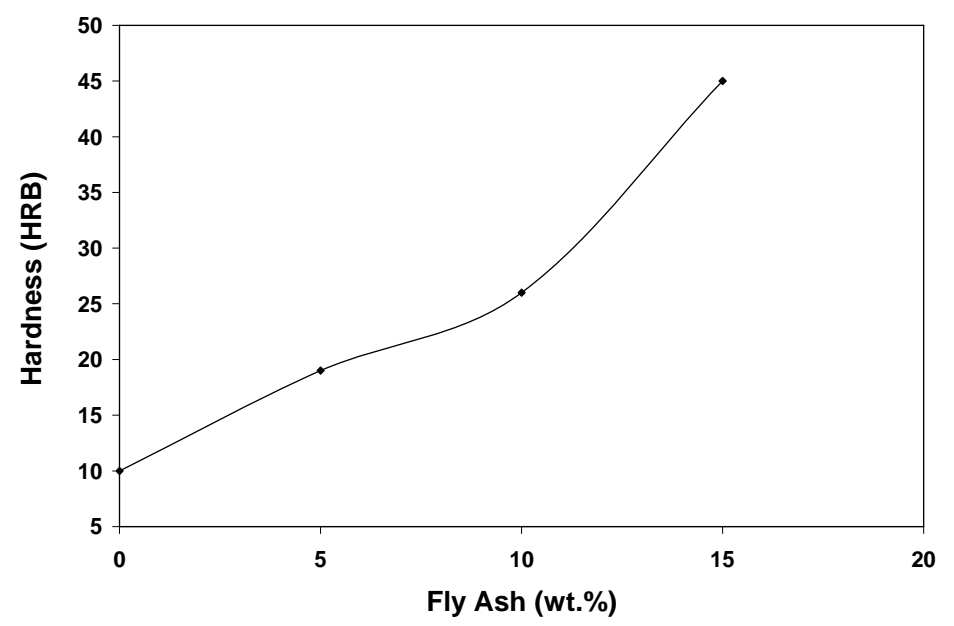

Figure 8: Effect of fly ash on hardness of pure aluminium in as cast condition

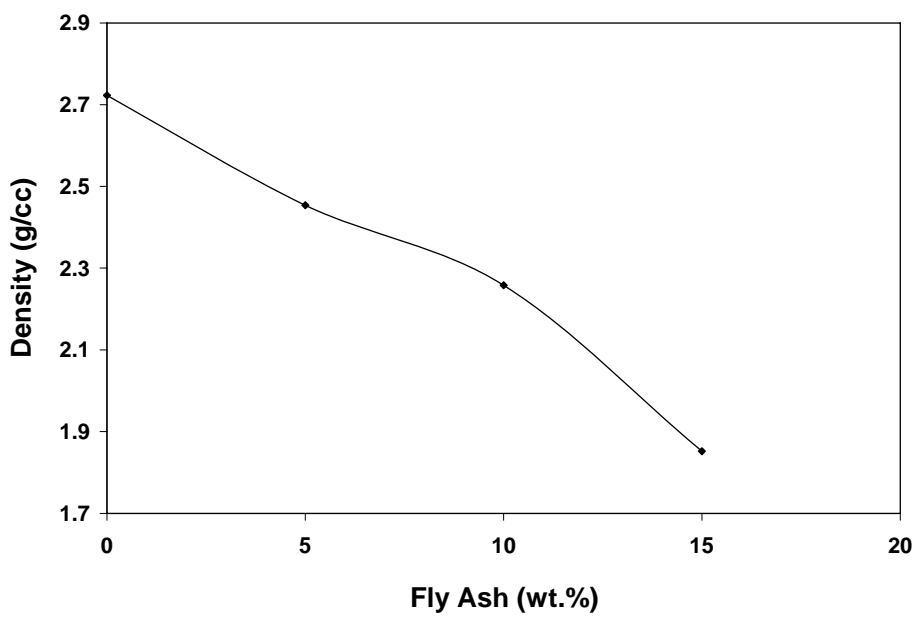

Figure 9: Effect of fly ash on density of the pure aluminium

Compressive deformation behaviour of the pure aluminium and ALFA composites can be understood by studying the engineering stress and strain curves. Figure 10 shows the engineering stress and strain curves for pure aluminium and composites during compression testing; the load requirement increased with increase in displacement for both the pure aluminium and ALFA composites. The composites show higher loads than the pure aluminium; and this increase is more for higher the amount of fly ash. This indicates that the fly ash addition leads to improvement in the strength of the composites. The strength of the MMC is expected to increase by addition of solid ceramic particles due to the strengthening effects occurred in particulate reinforced composites. These effects include the transfer of stress from the matrix to the particulate, the interaction between individual dislocations and particulates, grain size strengthening mechanism due to a reduction in composite matrix grain size, and generation of a high dislocation density in the matrix of the composite as a result of the difference in thermal expansion between the metal matrix and particulates (Natarajan et al., 2006; Akhlaghi et al., 2009; Valdez et al., 2008).

Figure 11 illustrate the influence of fly ash content on the compressive strength of pure aluminium and Al- fly ash composites in terms of hardness. As the deformation increases the hardness is increasing for the all the pure aluminium and ALFA composites; the rate of increasing is more for higher deformation with larger fly ash content. This might be due to the existence of strain hardening effects form matrix materials and also from the rule of mixture of composite strengthening (Callister, 2007). Figure 12 represents the undeformed and deformed cylindrical specimens of pure aluminium and ALFA composites at room temperature. According to an instability theory of fracture, ductile fracture will never occur in homogeneous deformation. On the other hand if the friction between the specimen and platens is more, the deformation becomes non uniform as a result of which, the barrel develops (Babu Rao et al., 2009). The present results (Figure 12) shows that with increasing the deformation the friction constraint was increased hence well developed barrel was generated for all the specimens. The extent of barrel for pure aluminium was less due to soft and low hardens values compared to rest of the specimens. For given deformation no crack was appeared for pure aluminium; whereas a well developed shear cracks were initiated for all the composites due to the presence of hard ceramic fly ash particles in the soft aluminium matrix. 


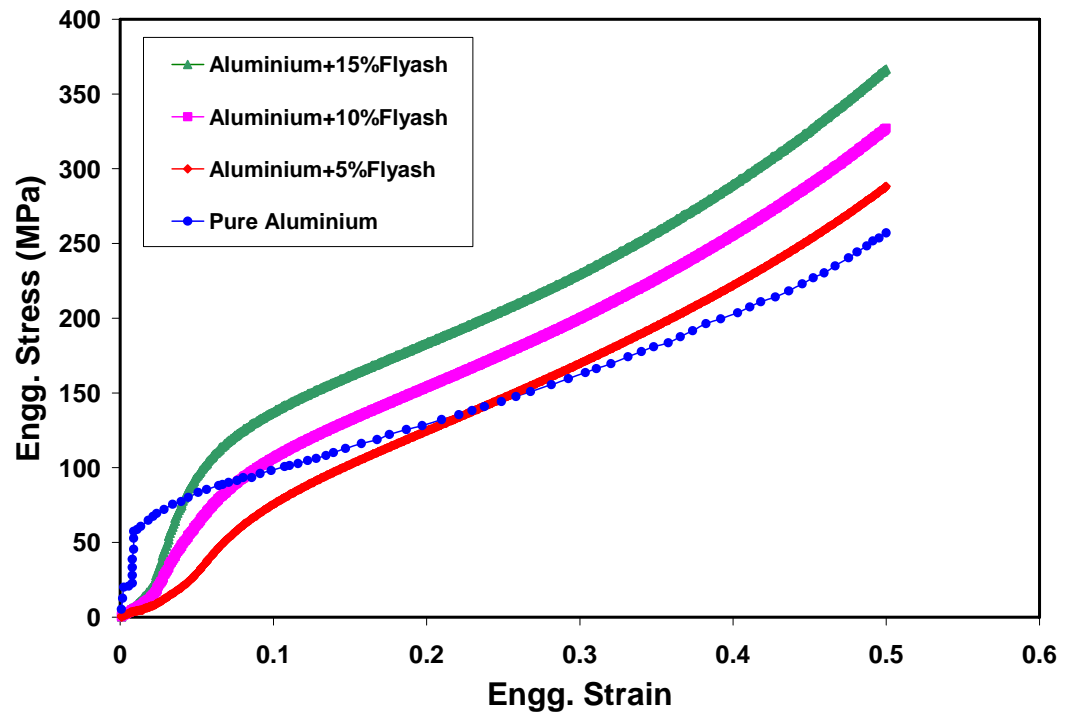

Figure 10: Engineering stress as a function of engineering strain for pure aluminium and ALFA composites with aspect ratio $(\mathrm{H} / \mathrm{D})=1.0$.

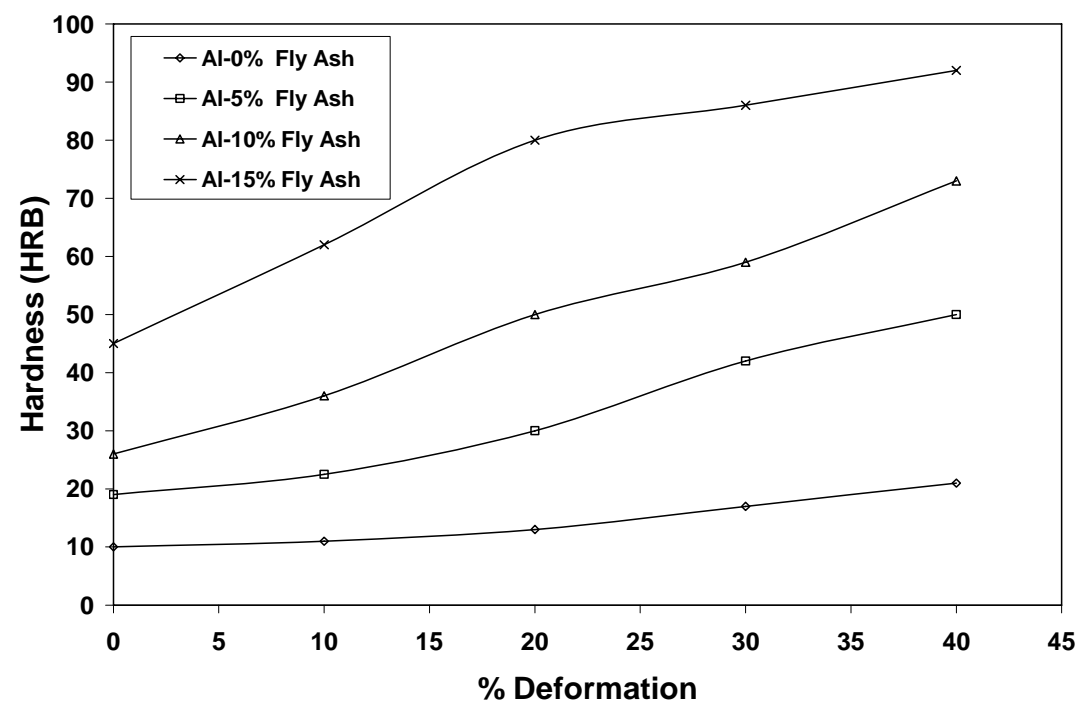

Figure 11: Hardness profiles of pure aluminium and ALFA composites at various Deformation stages under compression testing.

\begin{tabular}{lccccc}
\hline $\begin{array}{l}\text { \% Fly } \\
\text { Ash }\end{array}$ & $\begin{array}{c}\text { Before } \\
\text { Deformation }\end{array}$ & $\begin{array}{c}10 \% \\
\text { Deformation }\end{array}$ & $\begin{array}{c}20 \% \\
\text { Deformation }\end{array}$ & $\begin{array}{c}30 \% \\
\text { Deformation }\end{array}$ & $\begin{array}{c}40 \% \\
\text { Deformation }\end{array}$ \\
\hline & & & & & \\
\hline & & & & & \\
\hline
\end{tabular}

Figure 12: Pure aluminium and ALFA composites specimens showing bulge profiles at various deformation stages under compression testing $(\mathrm{H} / \mathrm{D}=1.0)$. 


\begin{tabular}{|c|c|c|c|c|c|}
\hline $\begin{array}{l}\text { \% Fly } \\
\text { Ash }\end{array}$ & $\begin{array}{c}\text { Before } \\
\text { Deformation }\end{array}$ & $\begin{array}{c}10 \% \\
\text { Deformation }\end{array}$ & $\begin{array}{c}20 \% \\
\text { Deformation }\end{array}$ & $\begin{array}{c}30 \% \\
\text { Deformation }\end{array}$ & $\begin{array}{c}40 \% \\
\text { Deformation }\end{array}$ \\
\hline 5 & & & & & \\
\hline
\end{tabular}

10
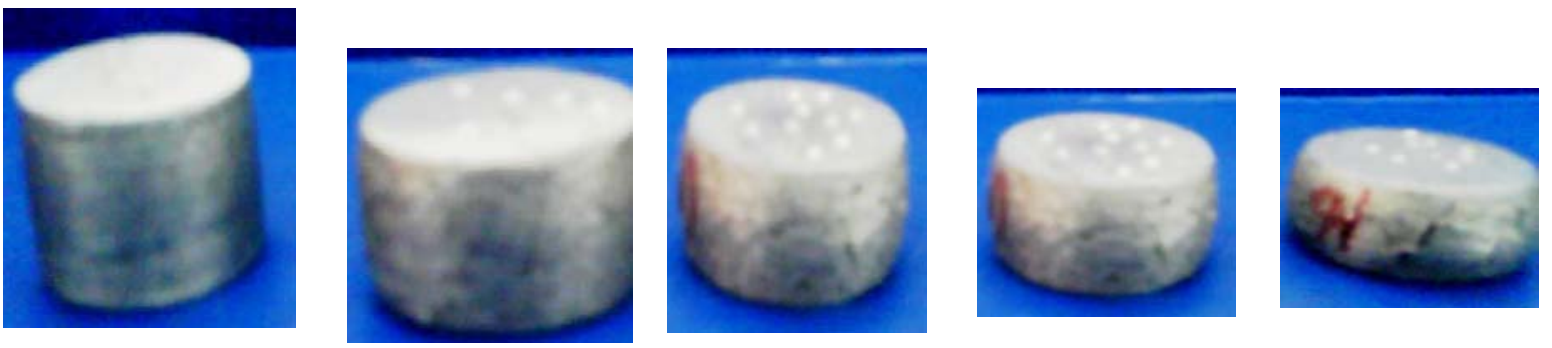

15
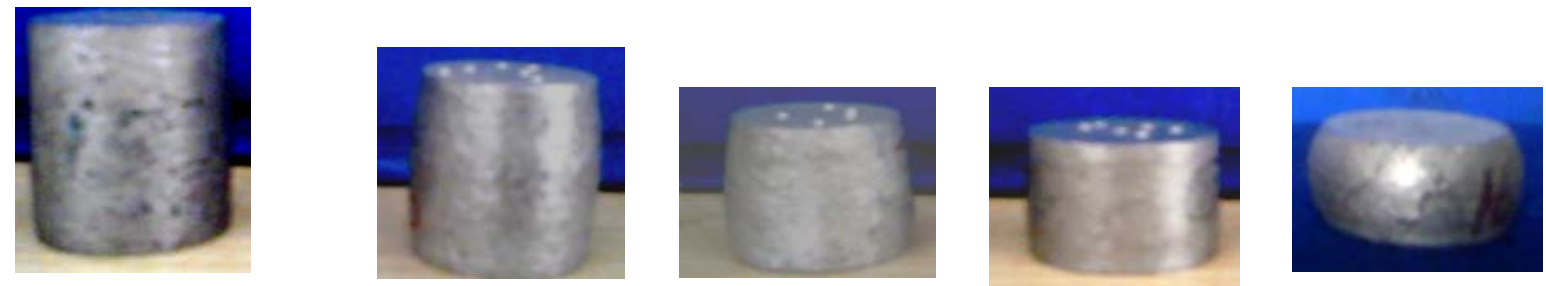

Figure 12 (cont'd): Pure aluminium and ALFA composites specimens showing bulge profiles at various deformation stages under compression testing $(\mathrm{H} / \mathrm{D}=1.0)$.

\section{Conclusions}

1. A series of Al - fly ash (ALFA) composites were produced by stir casting route successfully.

2. Large amount of fly ash up to $15 \%$ by weight was incorporated successfully into $\mathrm{Al}$ matrix by stir casting route.

3. There was a uniform distribution of fly ash particles in the matrix phase and also existing a good bonding between matrix and fly ash reinforcements.

4. The hardness of the composites increased whereas the density of the composites decreased with increasing the amount fly ash than the pure aluminium.

5. Enhanced mechanical properties were observed with increasing amount of fly ash under compression.

6. From this study it was concluded that industrial waste of fly ash was turn into industrial wealth by the production of light weight composites; these light weight ALFA composites can be used for automobile industry.

\section{Acknowledgements}

The authors thank the University Grants Commission - New Delhi, India for their financial support under UGC-MRP (File No: $34-396 / 2008$ (SR)) scheme; and Department of Metallurgical Engineering, Andhra University College of Engineering, Visakhapatnam, India for providing necessary support in conducting the experiments; and also Dr. K Siva Prasad, MME, NITTirchy, India for his support in SEM-EDX studies. Special thanks to RINL, Visakhapatnam Steel Plant, Visakhapatnam for their supply of fly ash for this study.

\section{References}

Akhlaghi F., Zare-Bidaki A., 2009, Influence of graphite content on the dry sliding and oil impregnated sliding wear behavior of Al 2024-graphite composites produced by in situ powder metallurgy method, Wear, Vol. 266, pp. 37-45.

Arsenault R..J., Wang L., and Feng C.R., 1991, Strengthening of composites due to microstructural changes in the matrix, Acta Metallurgica et Materialia, Vol. 39, pp. 47-57. 
Babu Rao J, Kamaluddin Syed, Appa Rao J, Sarcar M.M.M. and Bhargava N.R.M.R., 2009, Deformation behaviour of Al-4Cu2Mg alloy during cold upset forging, J. of Alloys and Compounds, Vol. 471, pp. 128-136.

Belger M.A., Rohatgi P.K., Gupta N., 2006, Aluminium composite castings incorporating used and virgin foundry sand as particle reinforcements, solidification processing of metal matrix composites - Rohatgi honorary symposium, TMS Annual Meeting, pp. 95-204.

Callister William D Jr., 2007, "Materials Science and Engineering- an introduction”, $7^{\text {th }}$ edition, John Wiley \& Sons. Inc.- New York, USA.

Hemanth Joel., 2009, Quartz $\left(\mathrm{SiO}_{2}\right.$ p) reinforced chilled metal matrix composite (CMMC) for automotive applications, Materials and Design, Vol. 30, pp. 323-329.

Mondolfo L.F., 1976, Aluminium alloys: structure and properties, The White friars Press Ltd, London.

Natarajan N., Vijayarangan S., Rajendran I., 2006, Wear behaviour of A356/25SiCp aluminium matrix composites sliding against automobile friction materials, Wear, Vol. 261,p. 812-822.

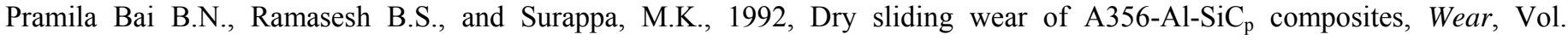
157, pp. 295-304.

Rajan T.P.D., Pillai R.M., Pai B.C., Satyanarayana K.G., Rohatgi P.K., 2001, "Proceedings of National conference on: Recent Advances in Materials Processing (RAMP - 2001), India, pp. 327-334.

Rohatgi P.K., Guo R.Q., Huang P., Ray S., 1997, Friction and abrasion resistance of cast aluminium alloy- fly ash composites, Metallurgical and Materials Transactions- A, Vol. 28, pp. 245-250.

Rohatgi P.K., 1994, Low-cost fly-ash-containing aluminum-matrix composites- overview, JOM - vol. 46, p. 55-59.

Rohatgi P.K., Schultz B.F., Daoud A., Zhang W.W., 2010, Tribological performance of A 206 aluminium alloy containing silica sand particles, Tribology International, Vol. 43, pp. 455-466.

Seah K.H.W., Hemanth J., Sharma S.C.., 2003, Mechanical properties of aluminium/quartz particulate composites cast using metallic and non metallic chills, Materials and Design, Vol. 24, No. 2, pp. 87-93.

Siddiquea R., Noumoweb A., 2008, Utilization of spent foundry sand in controlled ow- strength materials and concrete, Resources, Conservation and Recycling, Vol. 53, p. 27-35.

Sulaiman S., Sayuti M., Samin R., 2008, Mechanical properties of the as cast quartz particulate reinforced LM6 alloy matrix composites, J. of Materials Processing Technology, Vol. 201, pp. 731-735.

Surappa M.K., Rohatgi, P.K., 1981, Preparation and properties of cast aluminium -ceramic particle composites, J. Materials Science, Vol.16, pp. 983 - 993.

Valdez S., Campillo B., Perez R., Martinez L., Garcia A., 2008, Synthesis and microstructural characterization of Al-Mg alloy-SiC particle composite, Materials Letters, Vol. 62, pp. 2623-2625.

Vasudevan M., Surappa M.K; P. Ramakrishnan (Ed.), 1990, Proceedings of the International Conference on Advanced Composite Materials, Oxford \& IBH Publishing Co. Ltd., p. 265.

Wu G.H., Dou Z. Y., Jiang L. T., Cao J. H., 2006, "Damping properties of aluminium matrix - fly ash composites, Materials Letters, Vol. 60, pp. 2945-2948.

Zhiqiang Sun, Zhang Di, Guobin Li., 2005, Evaluation of dry sliding wear behaviour of silicon particles reinforced aluminium matrix composites, Materials and Design, Vol. 26, pp. 454-458.

\section{Biographical notes}

Dr. Babu Rao Jinugu, working as Associate Professor in the Dept. of Metallurgical Engineering, AU College of Engineering, Andhra University, Visakhapatnam since May 2000. He completed his B. Tech and M. Tech in Metallurgical Engineering from NIT Warangal and Ph. D from Andhra University, Visakhapatnam. Prior to join in this University, he worked as Assistant Manager (QA \& TD), R\&D division of RINL, Visakhapatnam Steel Plant, Visakhapatnam since Sept'1995April 2000 and also worked as Scientist in C-MET Laboratories, Dept of Electronics, Hyderabad for a period of two months (August - September 1995). He is the Life member for The Indian Institute of Metals (IIM) - Kolkata, Life Member for Tribology Society of India (TSI) and Life member for The Institution of Engineers (IEI). At present he is holding the positions of Joint Secretary - IIM Visakhapatnam Chapter, Chairman - IIM Visakhapatnam Students Chapter and Member- Editorial Board of IIM News Magazine. Currently working for UGC, New Delhi sponsored Major Research Project (File No: 34 -396/2008 (SR) on "Synthesis and Characterization of Al-Fly Ash Nano Composites" and also working for one AICTE, New Delhi sponsored research project (File No: 1-51/FD/CA/ (19)2006-2007) on "Studies on cold workability limits of Aluminium and its alloys". He was chosen by AICTE-New Delhi as "Career Award for Young Teacher" in the year 2007. He was visited Beijing, China and Singapore in the year 2008 for participation and presenting the papers at various international conferences. At present, a total of 53 Research Papers were published at various national and International journals/ conferences. His current areas of research are Nano Composite Materials and Metal Forming.

D. Venkata Rao, working as $\mathrm{Ph}$. D research scholar in the Department of Metallurgical Engineering, Andhra University, Visakhapatnam, India under the supervision of Dr. Babu Rao Jinugu and Dr. NRMR Bhargava.

Dr. NRMR Bhargava, working as Professor in the Dept of Metallurgical Engg, AU College of Engineering, Andhra University, Visakhapatnam, India. He completed his B. Tech in Metallurgical Engineering from NIT Warangal M. Tech from IT BHU, Varanasi and Ph. D from IISc Bangalore. He was visited China and Singapore in the year 2008 for participation and presenting the papers at various international conferences. At present, a total of 85 Research Papers were published at various national and International journals/ conferences. His current areas of research are Composite Materials, foundry and Metal Forming. At present he is working as Registrar, Adikavi Nannyya University, Rajahmundry, AP, India.

Received October 2010

Accepted December 2010

Final acceptance in revised form December 2010 